\title{
LAS CONSECUENCIAS ECONOMICAS DE LA INDEPENDENCIA IBEROAMERICANA
}

\author{
CARLOS NEWLAND
}

Universidad Carlos III de Madrid

En las Consecuencias económicas de la paz (1919), John M. Keynes alertaba a Europa que, aunque la victoria aliada en la Primera Guerra Mundial podía fortalecer la situación política y militar de los países vencedores, también podía tener repercusiones económicas y financieras desastrosas. Se refería, por supuesto, a Francia y a las exigencias de compensación económica que impuso a Alemania. Keynes aconsejaba que antes de tomar acciones de este tipo se estudiaran todos los efectos de una medida dada. Similar preocupación ocupó a historiadores y economistas de América Latina, España, Portugal y Estados Unidos, quienes durante tres días de julio se reunieron en la Universidad Carlos III de Madrid para discutir las consecuencias económicas del proceso independentista iberoamericano. En el seminario -auspiciado por la Fundación Banco de Bilbao-Vizcaya y la Sociedad Estatal Quinto Centenario- participaron, entre otros, los siguientes especialistas: Norberto Alvarez, Samuel Amaral, John Coatsworth, Astrid Cubano, Pedro Fraile, Jorge Gelman, Herbert Klein, Pedro Lains, Héctor Lindo Fuentes, Carlos Malamud, Zacarias Moutoukias, Marco Palacios, Mario Pastore, Jorge Miguel Pedreira, Leandro Prados de la Escosura (organizador del seminario), Alfonso Quiroz, Carlos Rodríguez Braun, Linda Salvucci, Richard Salvucci, Nicolás Sánchez-Albornoz, James Simpson, Enrique Tandeter y Gabriel Tortella. Los trabajos presentados y el debate - por momentos acalorado- comprendieron los siguientes temas.

\section{COSTOS Y BENEFICIOS DEL IMPERIO}

Una primera cuestión que se consideró fue el cálculo del beneficio que reportaba a España y a Portugal la posesión de sus colonias americanas. Estas ganancias incluían remesas directas de metales preciosos que iban a engrosar las arcas metropolitanas y los beneficios de un comercio monopó- 
lico (vender a un mercado cautivo productos caros y adquirir materias primas por debajo de su costo internacional). A esto se agregaba el monopolio de fletes y seguros, y su intermediación obligatoria en los bienes europeos adquiridos por las colonias y en la reexportación de los productos americanos. Para el caso de España, estos beneficios parecen haber estado en el orden del 3 al 4 por 100 del producto bruto: mayor era el impacto sobre el fisco, pues las transferencias de metales preciosos americanos representaban alrededor de una cuarta parte de su ingresos. En el caso de Portugal, los aportes coloniales eran superiores, alrededor del 8 por 100 del producto bruto, debido a la desproporcionada importancia de la economía del Brasil respecto de la lusitana. Pero en las dos naciones ibéricas ya se notaba hacia 1800 que estaban lentamente perdiendo en lo económico a sus colonias, ya que gran parte de su actividad se concentraba en la intermediación comercial y no en la venta de productos peninsulares. Por ello, las metrópolis no sufrieron una decadencia estructural con la pérdida de sus territorios y recuperaron sus niveles de ingreso después de un cierto tiempo. La carga no estaba distribuida equitativamente en América. México era de las regiones que más perdían por el arreglo colonial ( 7 por 100 del PIB), pero había regiones que ganaban, al ser receptoras de fondos ajenos que se utilizaban para cubrir los gastos públicos, como fueron los casos de Cuba, Puerto Rico, Buenos Aires y Centroamérica, que no lograban recaudar localmente lo suficiente. Una comparación de las ganancias coloniales ibéricas con las británicas muestra que España y Portugal se beneficiaron de sus posesiones americanas en un grado mucho más elevado que Gran Bretaña, debido a que en este último caso no existían las ventajas mencionadas (Gran Bretaña era, de todas maneras, el exportador de los productos maś baratos y no existía la transferencia unilateral de plata y oro).

\section{REGIONES BENEFICIADAS Y ESTANCADAS}

No es sorprendente que la independencia se originase en el Río de la Plata y Venezuela, ambos con un gran potencial exportador (especialmente en cueros), que estaba siendo obstaculizado por las restricciones coloniales. Aunque estas regiones ya se iban integrando al comercio internacional a través del contrabando, éste tenía altos costos, por lo que ansiaban una situación de librecambio. El caso de otros países, una vez independientes, fue distinto. Tanto Perú como México continuaron una decadencia económica ya insinuada a fines de la época colonial. La economía mexicana parece haber sufrido una caída de cerca del 25 por 100 del PIB durante el lapso 1800-1845 y sólo se recuperaría a mediados de siglo. El Perú no sólo se 
estancó hasta esa fecha - sobre todo en su antañamente importante producción minera-, sino que mantuvo políticas mercantilistas y proteccionistas. Otras situaciones negativas fueron las de Centroamérica (por ser mayoritariamente una economía de subsistencia) y la de Colombia, que mantuvo en gran parte su estructura colonial. Sorprendente el ejemplo de Cuba, que, aunque continuó como colonia, experimentó un crecimiento sostenido, debido a su destacada exportación de café y azúcar a los Estados Unidos. Brasil también viviría una situación de lento pero constante crecimiento y modernización, generada por su estabilidad institucional, porque, a pesar de que se independizó, lo hizo importando la monarquía portuguesa. Aunque las disparidades regionales fueron notables, todos se beneficiaron en alguna medida por el librecambio, que les permitía, por ejemplo, la importación de textiles baratos que afectaban positivamente incíuso a los sectores de menores recursos.

\section{LA DESTRUCCION DE LA GUERRA E INESTABILIDAD INSTITUCIONAL}

Lamentablemente para los patriotas americanos, a la separación de la metrópoli no siguió la esperada instauración de pacíficos regímenes democráticos similares al estadounidense. Por el contrario, en la mayoría de las nuevas naciones se produjeron intensos conflictos civiles, anarquía política y gobiernos militares y autoritarios. Desde el punto de vista económico, las guerras contra España y las civiles destruyeron al menos una parte del capital humano y físico existente. En Perú, por ejemplo, muchas minas de plata fueron inutilizadas y se retrajo la fuerza de trabajo. Por otro lado, se produjo una inseguridad que aumentaba los riesgos de cualquier inversión, además de que un buen porcentaje de los fondos que se podrían haber utilizado productivamente fueron destinados a financiar a los ejércitos, muchas veces mediante préstamos forzosos. El repudio de la deuda colonial fue otro factor que afectó la formación de un mercado de capitales.

\section{EL MARCO LEGAL}

Otro tema debatido fue el marco legal colonial y hasta qué punto fue reemplazado por otro nuevo, más moderno y eficiente, después de la independencia. Esto tiene gran importancia, puesto que las estructuras jurídicas afectan a la asignación eficiente de recursos. Los efectos beneficiosos de la eliminación de las barreras proteccionistas son bien conocidos, pero a éstos 
hay que agregar otros como la eliminación de los privilegios corporativos o gremiales, la aplicación de adecuados códigos comerciales y la privatización de recursos en manos del Estado (como tierras o la producción y venta del tabaco). Sin embargo, quedó claro en las discusiones que estas cuestiones necesitan más investigación y estudio, pues mientras algunas innovaciones independentistas afectaron positivamente a la economía, otras la perjudicaron -como el descubrimiento bonaerense de la emisión fiduciaria que terminó en una hiperinflación-. Asimismo, algunos países no cambiaron sus sistemas legales hasta mucho tiempo después, como fueron los casos de Perú y México.

El seminario, como ocurre en la mayoría de las reuniones de este tipo, generó más preguntas que respuestas, destacándose en todos los temas la necesidad de un conocimiento más profundo de las variables básicas cuantitativas que permitan evaluar mejor los problemas discutidos. Sobre algo no puede haber duda: si San Martín y Bolívar hubieran solicitado en 1809 a sus participantes una estimación de la tasa de retorno de la independencia, al conocer los resultados seguramente hubietan sido más cautos y prudentes en los procesos que ocasionaron, pero que luego no logratían controlar. 